\title{
The Determination of Academic Stress Levels by Gender and Year of Study. A Case of Kenyan University Students
}

\author{
Laigong Beatrice Chemutai \\ Shikuku M. Mulambula \\ Moi University, Department of Educational Psychology. \\ P.O. Box 3900-30100, Eldoret \\ Kenya
}

\begin{abstract}
The main purpose of this study was to determine the influence of gender, type of university, year of study and age on the level of stress among university students in Kenya. The study was conducted among Bachelor of Education students in universities located in western Kenya. The sample was 410 students with an equivalent number of male and female students. The study adopted a quantitative research design. Academic Stress Level (ASL) questionnaire was the main instrument used in collecting data. Data was analysed using t-test for the level of stress based on gender. One way ANOVA was used to determine the differences of stress level based on the year of study. The findings revealed a significant dissimilarity in the level of academic stress between male and female students. Female students were found to have higher stress level than the male students. The levels of stress also differed on the basis of the year of study with student in year three having higher levels of academic stress than those in the other years of study. Age and the type of university did not evident any significant influence on academic stress level. The study concluded that gender and the year of study significantly determined the level of academic stress among university students in Kenya. This study recommended that female students require more academic mentorship and be equipped with more stress coping mechanisms.
\end{abstract}

\section{Introduction}

\section{Academic stress level}

University education is surrounded by many challenges that students have to tackle in their grand effort towards attaining their degrees. Hussien and Hussien (2006) established that during their stay in the university, students suffer academic stress which results from testing, term papers and other demands within their environment. Misigo (2015) corresponds that even though university students encounter many exciting experiences they are equally faced with stress which impact on their psychological wellbeing as well as their academic achievement.

Academic activities may act as a source of pressure to most university students. Kamarudin, Aris, and Ibrahim (2009) render that too much stress can interfere with student's preparation, concentration, and performance but positive stress can be helpful to students as it motivates them to obtain peak performance.

In Kenyan universities students face numerous challenges during their study period emanating from their environment. The stress can be attributed to internal or external causes. Internal stress has to do with personal goals, expectations, standards, perceptions, desires, personality, problem-solving abilities, and social support system (Misigo 2015; Wangeri, Kimani and Mutweleli 2012). These internal stress causing factors influence the individual from within himself or herself. Misra and MacKean (2000) reiterate that stress conditions can be real or just perceived by the individual. External causes of stressors are forces from outside that cause stress for example unhealthy living environment or issues of relationships. An individual does not have much control over external stressors, because the source is more likely to be out of control. Achor, Crum, and Salovey (2013) observe that human brain reacts to causes of stress by releasing stress hormones equal to the degree of stress felt.

Other potential sources of stress include excessive homework, unclear assignments, and uncomfortable classrooms (Shannone, Bradley and Teresa, 1999). In addition to academic requirements, relations with faculty members and time pressures may also be sources of stress (May and Casazza, 2012). According Rajab, (2001) perception of stress by Jordanian dental students was higher than for other students for items relating to educational environment and personal or cultural aspects. These stressors are also common to many Kenyan university students where university life begins with a lot of excitement. Most of them find it is a time to be free from high schools and strict regulation and parental control (Misigo, 2015). With the onset of classes, they are given assignments, term papers and continuous assessment tests thus more exposure to academic stress. 
They are also given timelines for their work by their lecturers (Wangeri, Kimani \& Mutweleli, 2012). As they advance in their studies, the students find that university workload is significantly more involving than that of high school and it comes with less hand-holding from parents and tutors.

\section{Gender differences on academic stress level}

Levels of academic related stress differed among male and female students with female students leaning towards high academic stress level than their male counterparts (Abouserie, 1994; Bang, 2009; Misra \& Mckean, 2000). Higher levels of academic stress among female students can be attributed to negative appraisals and focus on the emotional challenges in the wake of the stressful event. Conversely male students are trained to display strength and machismo in the face of challenges right from their young age. This implies that male and female students might be experiencing academic stress but they differ in their way of expression. Pau et al. (2007) and Polychronopoulou and Divaris, (2005) states that perceived stress was reported in some research, to vary among different socio-demographic groups. For example, it was found that females, younger students, those without a previous higher education qualification, and those not satisfied with their decision to study dentistry were significantly more likely to report perceived higher level of stress when compared to their counterparts (Morse \& Dravo, 2007; Pau, Rowland \& Naidoo, 2007).

Although it has been demonstrated that there are other variables that can determine stress most studies across the globe have established that men and women report different reactions to stress, both physically and mentally. Morse and Dravo, (2007) relate that men and women attempt to manage stress in very different ways and also perceive their ability to do so and the things that stand in their way in markedly dissimilar ways. For example in America a survey by Piercall and Keim (2007) found that women are more likely than men to report having a great deal of stress and almost half of all women surveyed said their stress had increased over the past five years, in comparison to four in 10 men. Anbumalar, Dorathy, Jaswanti, Priya and Reniangelin (2017) state that females in India showed higher rates on perceived stress level than males among college students. The findings of this study are important since it utilised the the same statistical method with the current study. Nonetheless the characteristics of the population differ.

Female college students have manifested higher academic stress level than the male in most studies. The studies of Mazumdar, Gogoi, Buragohain and Haloi (2012) and Karaman, Lerma, Vela, and Watson (2019) in India and USA respectively, discovered that various symptoms that caused stress were more in females than males. Though the variables in the fore mentioned studies differed with those of the current study, it has been consistently found that there was a difference in stress levels between male and female college students. Al-Omari, (2005) found that there were no differences between male and female students in their perceptions of academic stress. The study demonstrated that more than half of the respondents were affected by depression and over two-thirds by anxiety and stress, and moreover female students reported higher scores of stress as compared to their male counterparts. On the contrary Kania (2014) found that there was almost no difference in stress levels between male and female students. The study had hypothesized that females would express higher stress levels than female students. This finding differed with other studies because it dwelt on specific factors.

\section{Stress level and the year of study}

Perception of stress can also differ according to the level of study. Elias, Ping, and Abdullah (2011) conducted a study in Malaysia that investigated stress and academic achievement. The study had a sample of 376 undergraduate students obtained through cluster sampling. The data was obtained through the use of college undergraduate stress scale (CUSS). The participants were compared using their year of study and the degree program they were pursuing. It found out that on average the undergraduate students had moderate level of stress. The first year students had low stress level while the final year students were the most vulnerable while the middle years had moderate levels. They also found that sitting for exams and class presentation were major sources of stress.

Alzhem, Molen and Boer (2013) carried out a study that purposed to find out if the year of study had an effect on stress levels among dental students. Dental environmental stress (DES) questionnaire was used to collect data. Causes of stress were examinations and completing clinical requirements. They found that the third year students reported the highest level of stress. Their study differed with the findings of this study since the sample was drawn from students pursuing different courses. The study relates to this study since both were based on the levels of stress and the year of study. There is little research on the influence of the year of study on stress level. Because of this comprehensive comparison with the present study could not be effectively achieved. 


\section{The purpose of the study}

Stress is mostly associated with working class and more often university student may not come to mind when stress is discussed. The purpose of the study was to examine the levels of stress among Bachelor of Education students in western Kenyan universities. It also aimed at investigating the influence of gender, university type, year of study and age on academic stress level.

\section{Materials and methods}

\section{Study area}

This study involved both public and private chartered universities in western part of Kenya. According to Geology.com (2008), the country borders the Indian Ocean and Somali to the east, southern Ethiopia and South Sudan to the North, Uganda to the West and Tanzania to the South. These are 31 Public universities, 5 public university constituent colleges, and 18 chartered private universities. This area was considered ideal for the study because of the presence of a good number of public and private universities. This region was also preferred because little research has been carried out on the same variables with the current study.

\section{Sample}

The sample was obtained from universities based in the Western region of Kenya. From the region the counties selected had at least one public or a private accredited university or a campus of the same. These universities were selected through purposive sampling. It was purposive because one of the requirements of the study was that the university involved should be offering a Bachelor of Education course. The study also expected that the students were present at the time of the study. The universities involved had the schools or faculties of education from which the sample was drawn from. Sharma (2017) points out that purposive sampling is the only appropriate method available if there are only limited numbers of primary data sources to contribute to the study. In the western region the number of universities is not very high in comparison to the number that was required and the reason why purposive sampling method was preferred. The study sample was obtained through stratified sampling technique.

\section{Instruments}

Questionnaire was the preferred method of collecting data because it would lead to quantified data. It also allowed the study to carry out statistical analysis. Quantification also enabled the results of the study to be compared and contrasted with other research. Furthermore quantitative data can be used to test research hypotheses and eventually create new theories (Popper, 2004).

Data on Stress levels were obtained through Academic Stress Level questionnaire (ASL) which had 13 items. The respondents stated the extent of stress level. Scoring of responses were as follows; not stressful (NS $=1$ ), slightly stressful ( $\mathrm{SS}=2)$, moderately stressful $(\mathrm{MS}=3)$, highly stressful $(\mathrm{HS}=4)$ and extremely stressful $(\mathrm{ES}=5)$. The maximum scores on academic stress levels were 65 and the minimum was 13. Scores ranging from 45-65 were considered as high level of stress, 35-44 as moderate stress level and 34 and below as low stress. Stress index was calculated by averaging the total score by the total number of items in the scale. The mean obtained was referred to as the Academic Stress Level Index (ASLI).

\section{Data analysis methods}

The statistical package for social sciences version 24 (SPSS) was used to run the data. The package was opted for since it gave room for computation of both descriptive and inferential statistics. It was also advantageous because it allowed easier management and precision of data. Besides the package was very flexible and includes procedures for producing tables and reports that are suitable to the user. Descriptive statistics used included frequency, percentages, mean, and standard deviation. These descriptive statistics enabled the researcher to describe the variables and summarize the data. Descriptive statistics simplified the data thus giving a better understanding of the same. T-test was used to analyse the academic stress level based on gender and one way ANOVA was used to analyse academic stress level based on the year of study.

Table 1: Gender and Academic Stress Level Cross tabulation

\begin{tabular}{llllll}
\hline Gender & Low stress & Moderate stress & High stress & Total & ASLI \\
\hline Female & $28(13.6 \%)$ & $61(29.7 \%)$ & $116(56.6 \%)$ & 205 & 2.4 \\
Male & $20(9.7 \%)$ & $91(44.3 \%)$ & $94(45.8 \%)$ & 205 & 2.4 \\
Total & 48 & 152 & 210 & 410 & 2.4 \\
\hline
\end{tabular}


The presentation in table 1 above indicates that there was an elevated frequency of female respondents with high academic stress level as compared to the male. However male respondents also had higher number of respondents with moderate stress level than the females. On the contrary female respondents also had a higher number with low stress as compared with the male respondents. On average both male and female students had moderate academic stress levels with equivalent academic stress level index (ASLI) of 2.4. Most students in Kenyan universities had high academic stress levels with female participants at $56.6 \%$ and male at $45.8 \%$. There is an indication of a greater percentage of high stress than the other categories of stress.

\section{Academic Stress Levels among University Students}

In attempt to achieve the objective of this study the hypothesis stated below was tested.

$\mathrm{HO}_{1}$ There is no significant difference in the academic stress level among university students based on gender, type of university, year of study and age.

The findings of hypothesis test are presented in tables 2 and 3 below.

Table 2: Group Statistics

\begin{tabular}{lllllll}
\hline \multirow{4}{*}{ ASL } & GENDER & $\mathrm{N}$ & Mean & Std. Deviation & Std. Error Mean \\
\cline { 2 - 6 } & male & 205 & 2.36 & .654 & .046 \\
\hline
\end{tabular}

Table 3: Independent Samples test for academic stress level based on gender

\begin{tabular}{llllll}
\hline & & \multicolumn{2}{l}{ Levene's test for equality of variances } & \multicolumn{2}{l}{ t-test for equality of means } \\
\hline \multirow{2}{*}{ ASL } & Equal variance assumed & F & Sig. & t & Df \\
& Equal variance not assumed & & .046 & -1.004 & 408 \\
\cline { 2 - 6 } & & & -1.004 & 404.130 \\
\hline
\end{tabular}

Table 2 above indicates that female students had a higher mean for academic stress level than the male students. The ttest presented in table 3 above indicates a significance level of 0.046 which is less than 0.05 . The null hypothesis was therefore rejected meaning that there was a significant difference in the academic stress level among university students based on gender. This implied that the female students had higher stress levels than the male students. This is because female students perceive stressful events differently from male students.

\section{Academic stress level and the year of study}

The year of study was also an important demographic variable of this study. Bachelor of education degree takes four years in Kenya and therefore respondents were drawn from each year of study. Stress levels based on the year of study was described as shown in Table 4 below.

Table 4: Year and Academic Stress Level Cross tabulation

\begin{tabular}{cclllc}
\hline Year of study & Low stress & Moderate stress & High stress & Total & ASLI \\
Year 1 & $22(22 \%)$ & $35(35 \%)$ & $43(43 \%)$ & $100(24.4 \%)$ & 2.2 \\
Year 2 & $12(12.4 \%)$ & $36(37.1 \%)$ & $49(50.1 \%)$ & $97(23.7 \%)$ & 2.4 \\
Year 3 & $6(5.7 \%)$ & $37(34.9 \%)$ & $63(59.4 \%)$ & $106(25.8 \%)$ & 2.5 \\
Year 4 & $8(7.5 \%)$ & $44(41.1 \%)$ & $55(51.4 \%)$ & $107(26.1 \%)$ & 2.4 \\
Total & $48(11.7 \%)$ & $152(37.1 \%)$ & $210(51.2 \%)$ & 410 & 2.4 \\
\hline
\end{tabular}

The fourth year students had the highest representation followed by the third, first and second years as shown in table 4 above. There were more students with high stress from the third year group with 59.4\% as compared to the first, second and fourth year students. The fourth year students also reported high stress at $51.4 \%$. 
This implies that academic pressure is higher in the third and fourth years of study. There were a greater percentage of high stress levels compared to moderate and low stress across all the years of study. The ASLI indices show that third year education students had high academic stress levels (ASLI $=2.5$ ). On average the first, second and fourth year respondents had moderate academic stress levels indices. The third year students were experiencing this due to higher academic pressure and inability to manage time.

Table 5: Descriptive for academic stress level based on the year of study

\begin{tabular}{llllllll}
\hline Year & $\mathrm{N}$ & Mean & Std. Deviation & Std. Error & \multicolumn{2}{l}{ 95\% Confidence Interval for Mean } & Minimum \\
& & & & & Lower Bound & Upper Bound & \\
1 & 100 & 2.21 & .782 & .078 & 2.05 & 2.37 & 1 \\
2 & 97 & 2.38 & .699 & .071 & 2.24 & 2.52 & 1 \\
3 & 106 & 2.54 & .604 & .059 & 2.42 & 2.65 & 1 \\
4 & 107 & 2.44 & .632 & .061 & 2.32 & 2.56 & 1 \\
Total & 410 & 2.40 & .689 & .034 & 2.33 & 2.46 & 1 \\
\hline
\end{tabular}

The findings in Table 5 above describe the number of respondents according to the year of study and their means for the academic stress level and standard deviations. The findings show the mean range through the years of study. However the third years had the highest mean of 2.54 and the first years had the lowest with 2.21 . This meant that third year students had the highest levels of academic stress. The students in the other years had moderate levels of academic stress. This is because the students in the third have higher academic demands as compared to the other years.

Table 6: One way ANOVA for academic stress level based on the year of study.

\begin{tabular}{|c|c|c|c|c|c|}
\hline & $\begin{array}{l}\text { Sum } \\
\text { Squares }\end{array}$ & of $\mathrm{df}$ & Mean Square & $\mathrm{F}$ & Sig. \\
\hline Between Groups & 5.809 & 3 & 1.936 & 4.178 & .006 \\
\hline Within Groups & 188.181 & 406 & .463 & & \\
\hline Total & 193.990 & 409 & & & \\
\hline
\end{tabular}

Anova test in table 6 above indicate that there was a statistical significant difference among students on the level of stress based on the year of study with $p=.006$ less than alpha .05 . This implied that the year of study had a significant influence on the academic stress level. The university students' expression of academic stress significantly varied at different years of study.

\section{Discussion}

This study found that a higher percentage of participants experienced high levels of academic stress as per the descriptive statistics based on gender. The descriptive statistics indicate that there was a larger percentage of female with high stress than the male respondents. The t-test also revealed that there was a significant influence of gender on academic stress. This confirms the statement of Misra, McKean, West and Russo (2000) that stress levels vary by gender of students. The findings concur with those of Misra and McKean (2000) who found that female students were more prone to academic stress because of negative appraisal and focus on emotional feelings when experiencing a stressful event. On the contrary males are trained to display strength when undergoing challenges. Dahlin, Joneberg and Runeson (2005) also established that female students had higher ratings than male on four out of seven stress factors. Reddy, Menon and Thatti (2018) similarly established that male and female students did not differ on total academic stress but the dimensions of academic stress differed significantly across gender with female students having higher mean on the same than the male students. The findings of the reviewed studies confirm that gender difference exist in academic. This study is in agreement with other findings across the globe even though population characteristics and backgrounds differ.

The year of study was found to have a significant influence on the level of stress with $p=.006$ less alpha $=.05$. This was an indication that university students in Kenya experienced different levels of stress at varied years of study. This agreed with the findings of a study among university students in Brazil by Carmo et al. (2016). The study concluded that as the students advanced in their years of study their level of stressed went up. It was also in agreement with a study by Hamurcu (2018) who revealed that fourth year students had higher expectations about their academic success and their life in the future and therefore, they experienced more severe educational stress. The study used subscale self-expectation which had items about hopes for the future, the finding is indicative of their stress and anxiety about their life in the future. The current study is in conformity with fore mentioned researches despite the differences in location of the study. However there is limited research basing academic stress to the year of study. 


\section{Conclusion}

This study investigated academic stress levels among university students based on gender, type of university, the year of study and age. The study found that academic stress level among Bachelor of Education students in Kenya was generally moderate. Moderate stress level is good for students' academic performance in comparison with high stress levels that can negatively affect students while low stress level can lead to low stimulation. Female students were more vulnerable to high academic stress than the male students. This can be attributed to differentiated appraisal of stressful events by male and female students. This study also established that third year students had higher academic stress level than those in the other years of study. By their third year of study in most universities in Kenya, Education students engage more in practical work thus increasing their workload. This could place a higher academic demand on students requiring them to take individual responsibility. At this stage students may also get more concerned with their course work as the realities of future profession dawns on them. This therefore implies that students should be given clear timelines on their academic activities. Course work cannot be reduced nor can stress be eliminated but if students are properly guided to be more responsible towards their academic work, stress levels can be brought to an optimum level. However there is limited research basing academic stress on the year of study to enable a conclusive comparison.

\section{Recommendation}

This study has shown that the levels of stress are generally moderate but higher among certain groups. Stress may not be eliminated and certain levels of stress are necessary. Female students can be given more awareness on stress and be equipped with more coping mechanisms Deliberate effort should be made to constantly create awareness on causes and effects of stress to students to all university students. This will help students deal with academic stress and other emerging issues in the modern world. Female mentorship programmes could also be introduced to help the female student to cope with stress. Female students have unique challenges that are different from those of the male students. It is also necessary to conduct more research in the same area of study on academic stress level using other methods of research. This will provide more information for comparison.

\section{References}

Abouserie, R. (1994). Sources and levels of stress in relation to locus of control and self-esteem in university students. Educational Psychology, 14, 323-330.

Achor, S., Crum, A. J. \& Salovey, P. (2013). Rethinking Stress: The Role of Mindset in Determining the Stress Response. Journal of Personality and Social Psychology, 104 (4), 716-733.

Al-Omari W. M. (2005) Perceived sources of stress within a dental educational environment. Journal of Contemporary Dental Practice, 6: 64-74.

Anbumalar C., Dorathy A. P., Jaswanti V.P., Priya D. \& Reniangelin D. (2017). Gender Differences in Perceived Stress levels and Coping Strategies among College Students. The International Journal of Indian Psychology, 14(4)22-33

Alzhem, A.M., Molen, H. T. \& Boer, B. J. (2013). Effects of year on stress levels in male undergraduate dental students. Advances in Medical Education and Practice, 4; 217-222

Bang, E. (2009). The effects of gender, academic concerns, and social support on stress for international students. Retrieved April, 06, 2012 from https://mospace.umsystem.edu/

Carmo, L. S., Ferreira, J. L., Affonso1, M. J., Pereira, A. Q., Belintani1, P. and Filho I. Z. (2016). Stress into University Students Impacts the Learning Quality. Journal of Psychology \& Psychotherapy, 6(2); 54-64.

Cronbach, L. J. (1984). Essentials of psychological testing ( $4^{\text {th }}$ ed.) New York: Harper \& Row.

Dahlin, M., Joneborg, N. \& Runeson, B. (2005). Stress and depression among medical students: a cross-sectional study. Medical education, 39(6):594-604.

Elias, H., Ping, W. S. \& Abdullah, M. C. (2011). Stress and academic achievement among undergraduate students in universiti Purta Malaysia. Procedia-Social and Behavioral Sciences. 29; 646-655.

Hamurcu H. (2018). Examination of attitudes to learning and educational stress in prospective primary school teachers: Educational Research and Reviews, 31 (2), 92-105.

Hussien, T. and Hussien, S. (2006). Strategies for Coping Educational and Psychological Stress. Dar Alfiker. Amman.

Kamarudin, R., Aris, A. \& Ibrahim N. (2009). Stress and academic performance: a study among pre-science students in UiTM Negeri Sembilan. Conference on Scientific \& Social Research, 8(9), 9-15.

Kanai, S.K. (2014). The relationship between gender differences and stress. The Huron University College Journal of Learning and Motivation. 52(1), 7.

Karaman, M. A., Lerma, E., Vela, J.C. \& Watson, C.J. (2019). Predictors of academic stress among college students. Journal of College Counseling, 22(1), 41-55. 
Lazarus, R. S. (1984). On the primacy of cognition. American Psychologist, 39: 124-129.

May, R. W., \& Casazza, S. P. (2012). Academic major as a perceived stress indicator: Extending stress management intervention. College Student Journal, 46(2), 264- 273.

Misigo, B. L. (2015). Gender difference in the perceived level of stress and coping strategies among university students in Kenya: A case of public universities. International Academic Journal of Social Sciences and Education, 1 (4), 44-52.

Misra, R. \& McKean, M. (2000). College students academic stress and its relation to their anxiety, time management and leisure satisfaction. American Journal of Health Studies. 16 (1):41-50.

Morse Z \& Dravo U. (2007). Stress levels of dental students at the Fiji School of Medicine. European Journal of Dental Education, 11: 99-103.

Piercall E. A. \& Keim M. C. (2007). Stress and coping strategies among community college students. Community College Journal of Research and Practice, 31(9), 703-712.

Polychronopoulos, A., \& Divaris, K. (2005). Perceived sources of stress among Greek dental students. Journal of dental education, 69(6), 687-692.

Popper, K. (2004). The Logic of Scientific Discovery. New York, Routledge, Taylor \& Francis.

Shannone, R. E., Bradley, C. \& Teresa, H. M. (1999). Sources of stress among college students. College Students Journal, 33(2); 340-374.

Rajab, L. D. (2001). Perceived sources of stress among dental students at the University of Jordan. Journal of Dental Education, 65: 232-241.

Yap, A. J., \& Tong, E. M. (2009). The Appraisal Rebound Effect: Cognitive Appraisals on the Rebound. Personality and Social Psychology Bulletin, 35(9):56-78. 